\title{
A contribuição de Wallon para o desenvolvimento e aprendizagem da criança autista
}

\author{
Maria Almerinda de Souza Matos ${ }^{1}$, Gisella Vieira Braga ${ }^{2}$, Maria Norma \\ Magalhães Stelli ${ }^{3}$, Natália dos Santos Chaves ${ }^{4}$, Raimunda Maria \\ Moreira da Silva ${ }^{5}$, Samuel Vinente da Silva Junior ${ }^{6}$
}

RESUMO: Este trabalho objetiva avaliar a Intervenção Pedagógica com base na Teoria de Henri Wallon em educandos com autismo, oportunizando-lhes subsídios para maior interação no convívio social. Foram atendidos cinco alunos do Centro de Vivência Magnólia - AMA, em parceria com o Núcleo de Estudos e Pesquisas em Psicopedagogia Diferencial - NEPPD, no segundo semestre de 2010, cujos resultados revelaram avanços significativos no comportamento dos mesmos.

Palavras-chave: autismo, educandos, intervenção pedagógica, teoria Walloniana.

Área Temática: Educação

\footnotetext{
${ }^{1}$ Professora da Universidade Federal do Amazonas - NEPPD/FACED/UFAM - ufamneppd@gmail.com

2 Pesquisador/a da Universidade Federal do Amazonas no Núcleo de Estudos e Pesquisas em Psicopedagogia Diferencial - NEPPD.

3 Pesquisador/a da Universidade Federal do Amazonas no Núcleo de Estudos e Pesquisas em Psicopedagogia Diferencial - NEPPD.

${ }^{4}$ Pesquisador/a da Universidade Federal do Amazonas no Núcleo de Estudos e Pesquisas em Psicopedagogia Diferencial - NEPPD.

5 Pesquisador/a da Universidade Federal do Amazonas no Núcleo de Estudos e Pesquisas em Psicopedagogia Diferencial - NEPPD.

6 Pesquisador/a da Universidade Federal do Amazonas no Núcleo de Estudos e Pesquisas em Psicopedagogia Diferencial - NEPPD.
} 


\section{Wallon's contribution to the development and learning of autistic children}

ABSTRACT: This study evaluates an educational intervention based on the theory of Henri Wallon in students with autism, providing them opportunities and subsidies for greater interaction in social life. There were five students who attended the Experience Center, Magnolia-AMA, in a partnership with the Center for Studies and Researches on Educational Psychology Differentia l - NEPPD, in the second half of 2010. Results showed significant improvements in the students behavior. Keywords: autism, pupils, educational intervention, theory Wallonian

Thematic area: education

\section{Wallon contribución al desarrollo y el aprendizaje de los niños autistas}

RESUMEN: Este estudio evalúa la intervención educativa basada en la teoría de Henri Wallon en alumnos con autista, proporcionando oportunidades para que las subvenciones para una mayor interacción en la vida social. Hubo cinco estudiantes asistieron al Centro de Experiencia, Magnolia - AMA, en colaboración con el Centro de Estudios e Investigación en Psicología de la Educación Diferencial-NEPPD en el segundo semestre de 2010 y los resultados mostraron mejorías significativas en el comportamiento de ellos.

Palabras clave: autismo, alumnos, intervención educativa, teoria $W a-$ loniana.

Área temática: educación 


\section{INTRODUÇÃO}

O autismo corresponde aos Transtornos Globais do Desenvolvimento (MARQUES, 2000), classificado, conforme o Manual Diagnóstico e Estatístico de Transtornos Mentais, como: Transtorno Autista, Transtorno de Rett, Transtorno Desintegrativo da Infância, Transtorno de Asperger e Transtorno Global do Desenvolvimento sem Outra Especificação (Associação Psiquiátrica Americana, 2004). Padrões classificatórios são também propostos pela Organização Mundial de Saúde (OMS), na publicação Transtornos Mentais e de Comportamento, onde o autismo é categorizado como Transtornos Invasivos do Desenvolvimento (OMS, 1993).

Segundo Frith (1996), o autismo foi identificado como um transtorno precoce do desenvolvimento infantil afetando o desenvolvimento mental da criança por toda a extensão de sua vida. Os sintomas modificam-se ao longo do ciclo vital, sendo que algumas características só aparecem mais tardiamente e outras desaparecem com o tempo, o que torna sua compreensão um grande desafio estudado e pesquisado em diversas áreas do conhecimento. O autismo é também um dos transtornos mais estudados em neuropsiquiatria, tendo em vista a sua gravidade e o impacto que produz, mas, apesar de décadas de pesquisas e investigações, sua etiologia permanece indefinida, pois os resultados apontam respostas complexas e diversificadas (FRITH, 1996).

Diferentes literaturas abordam a criança com autismo, entre elas o estudo clássico de WING (1993), o qual realizou observações com crianças autistas inglesas na década de 70. Tal estudo permitiu-lhe concluir que todas as crianças com diagnóstico do autismo apresentam uma tríade com características específicas, que veio a ser conhecida e adotada internacionalmente como Tríade de Lorna Wing, por envolver transtornos da interação social, da comunicação e da função simbólica.

Diversos métodos e teorias têm sido desenvolvidos, buscando com isso "responder" às condutas e manifestações advindas do portador do autismo, manifestações essas difíceis de serem compreendidas nos meios sociais, educativos e familiares. (MACHADO, 2005, p.9).

O uso da expressão espectro do autismo, cunhada por WING (1985), em substituição ao termo autismo, deve-se à constatação da existência de amplas variações entre as condutas dos portadores, revelando, segundo (MARQUES, 2000), variada caracterização: a) 
maior ou menor gravidade do transtorno; b) associação com outras alterações; c) competências comunicativas, cognitivas e interpessoais diferenciadas; e) variações de condutas pessoais em relação ao mesmo transtorno.

Estima-se que 21 em cada 10.000 crianças nascidas apresentam características do autismo (MARQUES, 2000). Tais dados e o reconhecimento do autismo como quadro clínico diferenciado de outros transtornos mentais têm influenciado estudos e pesquisas objetivando clarificar suas causas e, sobretudo, promover intervenções de toda ordem que viabilizem o seu desenvolvimento, bem como a acessibilidade desses indivíduos às propostas educacionais.

No Brasil, na última década, em decorrência de movimentos em prol dos direitos humanos e pela intervenção ativa dos familiares de autistas, já se percebem iniciativas visando à promoção de oportunidades educacionais para educandos com transtornos do autismo. Entretanto, o desafio que se apresenta aos professores é o de conseguir lidar com os comportamentos diferenciados desses alunos, que manifestam atitudes como: gritar, correr e agredir. Diante desse contexto, alguns professores, por desconhecimento dos aspectos que envolvem a síndrome, classificam esses alunos como doentes, isolados, alheios ao mundo e sem perspectivas de aproveitamento pedagógico. Essa visão linear e homogeneizante nivela todos com perturbações do autismo, a despeito da comprovada diferenciação entre eles.

Compreende-se que os educandos autistas enfrentam muitas dificuldades em ambientes educacionais, uma vez que os níveis de comprometimento cognitivo são diferenciados. Alguns demonstram dificuldade de organização, déficit de atenção, agressividade, dificuldade de sequenciar, dentre outras características próprias da síndrome. Entretanto, é preciso que a escola seja um espaço que estimule a manifestação de potencialidades, a integração e o crescimento individual e social dos autistas.

Nesse sentido, segundo Camargos (2002), um fator que vem contribuindo positivamente para a comprovada eficácia das intervenções educativas nos atendimentos de crianças autistas é a incorporação de atividades psicoeducacionais, indicando melhor desenvolvimento das crianças que participam dessas atividades em comparação a outras que recebem atendimentos de outra ordem. 


\section{HISTÓRICO}

O termo autista surgiu na literatura psiquiatra em 1906, quando Plouller estudava pacientes que possuíam o diagnóstico de demência precoce ou esquizofrenia. Contudo, o termo autismo foi difundido primeiramente por Bleuler (1911), que se referiu ao termo como transtorno básico da esquizofrenia e definido como perda de contato com a realidade, causada pela impossibilidade ou grande dificuldade de comunicação interpessoal.

Em 1943, o psiquiatra infantil Léo Kanner descreveu o autismo pela primeira vez com o nome de Distúrbios Autísticos do Contacto Afetivo ao observar onze crianças que possuíam um quadro caracterizado por isolamento extremo, dificuldade de relacionar-se com pessoas e uma estranha predileção por objetos.

Kanner (1943), ao contrário de Bleuler, defendia que os autistas não se enquadravam no quadro de esquizofrenia, diferenciando o autismo de outras psicoses graves na infância. Enquanto Bleuler afirmava que o autismo era um sintoma secundário da esquizofrenia, Kanner, embora concordasse com a semelhança de algumas das características apresentadas, como o desejo de isolar-se do mundo, por exemplo, afirmava que o autista nem ao menos conseguia penetrar no mundo (OLIVEIRA, 2001).
[...] enquanto o esquizofrênico tenta resolver seu proble- ma deixando um mundo do qual faz parte e com o qual esteve em contato, nossas crianças gradualmente estabe- lecem compromissos estendendo tentáculos circunspec- tos em um mundo no qual têm sido estrangeiros desde o início (KANNER, 1943, apud OLIVEIRA, 2001, p. 32).

Atualmente, o autismo é considerado como uma síndrome comportamental, com múltiplas etiologias consequentes a um distúrbio do desenvolvimento, de acordo com Assumpção Júnior (1998), relatado como um quadro que se inicia antes dos três anos de idade, com predomínio maior em indivíduos do sexo masculino.

\section{Atendimento pedagógico às crianças autistas}

$\mathrm{O}$ atendimento pedagógico às crianças autistas exige um trabalho sistemático no que tange à estrutura, ao espaço e principalmente à preparação da equipe, tudo para que se possa proporcionar um ambiente estimulante ao desenvolvimento das potencialidades, à integração e ao crescimento individual. As atividades não devem se limitar aos conteúdos programáticos, mas priorizar a melhoria da 
qualidade de vida do educando, contribuindo, assim, para o melhor convívio familiar e social.

Segundo Camargos (2002, p. 122), a educação é um processo dialético, ocorre como fruto da interação entre seres humanos e entre eles e a estrutura no qual estão inseridos, sendo um processo dentro do qual o aprender e o ensinar são simultâneos. Dessa forma, faz-se necessário um olhar ampliado no sentido de observar o aspecto global desse processo, abarcando todas as pessoas envolvidas: educandos, pais, professores, técnicos e funcionários.

A intervenção pedagógica na escola tem início com base nos estudos que abrangem a análise pedagógica e social para que se possa compreender a criança enquanto ser e suas necessidades. A partir de então, devem ser levantadas estratégias para o planejamento da intervenção, que deve estar pautada no respeito às diferenças e a outros padrões estéticos e culturais.

Uma intervenção pedagógica embasada na teoria de Henri Wallon [...] deve dirigir-se à pessoa global e transformar-se em instrumento para seu desenvolvimento, o que pressupõe a integração entre as dimensões afetivas, cognitiva e motora. Outro principio mostra que a ação educativa deve fundamentar-se nos conhecimentos da natureza infantil, com suas características, ou seja, no estudo psicológico da criança. Por fim o saber escolar não pode dissociar-se do meio físico e social onde a atividade infantil encontra alternativas de realização, mas sim nutrir-se das possibilidades que ele oferece. (BOATO, 2009 p. 65).

No processo de aplicação das atividades, é importante que essas ocorram naturalmente, para que se tornem significativas e favoráveis à criação de vínculo e à formação do autoconceito da criança, pois, quando não ocorre dessa maneira, poderá ocorrer falta de interesse da criança com a atividade proposta, impedindo-a de participar em atividades posteriores. Nesse sentido, Camargos (2002, p. 123) propõe algumas estratégias que podem ser usadas: sensibilizar a criança para o seu próprio corpo; estimular as percepções sensoriais; procurar despertar interesse para objetos, brinquedos e atividades que proporcionem resposta rápida; provocar a focalização do olhar; favorecer o desenvolvimento do autocontrole através da interiorização de controles externos.

Devido à limitação da criança autista no que diz respeito à capacidade de abstrair frustrações e/ou adiar satisfações, fazer associações e imitações, bem como todos os seus comportamentos este- 
reotipados, é importante desenvolver algum tipo de comunicação alternativa, em busca da compreensão desse comportamento. A afetividade é fundamental nesse processo, pois as crianças com autismos necessitam de maior atenção e estímulo que outras crianças; para que a afetividade se estabeleça, é necessário que o professor tenha sensibilidade para interpretar os desejos dos alunos.

Por afetividade, nessa proposta entende-se o conjunto de manifestações de fenômenos psíquicos que se apresentam sob a forma de emoções e de sentimentos, acompanhadas sempre da impressão de prazer ou desprazer, satisfação ou insatisfação, agrado ou desagrado, alegria ou tristeza. (BOATO, 2002 p.69)

Nesse contexto, buscou-se fundamentar o processo da Intervenção Pedagógica operacionalizado no Núcleo de Estudos e Pesquisas em Psicopedagogia Diferencial - NEPPD, da Faculdade de Educação da UFAM, com uma teoria que pudesse abranger o educando na sua dimensão global. Nesse aspecto, a Teoria das Emoções e da Psicogênese de Henri Wallon apresenta todas as possibilidades de realização de uma intervenção pedagógica, possibilitando ao educando com autismo o desenvolvimento de suas potencialidades, dentro dos limites de cada indivíduo.

\section{A Teoria de Henry Wallon}

Henri Wallon (1879-1962) nasceu na França, estudou filosofia, medicina e psicologia e em seus estudos sempre demonstrou uma clara aproximação com a educação, já que via a escola como meio peculiar à infância e obra fundamental da sociedade contemporânea. Galvão (1998) afirma que, para Wallon, a pedagogia ofereceria um campo de observação e também questões para investigação e para a construção do conhecimento no processo do desenvolvimento infantil, oferecendo, dessa forma, importante instrumento para o aprimoramento da prática pedagógica.

Wallon sugeria, então, que a pedagogia fundamentasse as atividades na relação recíproca entre o homem e o seu meio social, dando ao aluno recursos para o desenvolvimento de todas as suas potencialidades, não para usufruí-las individualmente, mas para a transformação social, para a construção de uma sociedade mais justa e igualitária. (GALVÃO 1998, p.29).

Wallon desenvolveu várias pesquisas na área da neurologia onde propôs o estudo do desenvolvimento infantil, contemplando os as- 
pectos da afetividade, da motricidade e da inteligência. Estudou, também, o desenvolvimento infantil, primeiramente, na interação entre o equipamento motor e a afetividade do recém-nascido e, depois, entre a criança e o campo social. Wallon considera que é contra a própria natureza estudar a criança de maneira fragmentada, pois em cada estágio do seu desenvolvimento ela constitui um todo indivisível, apesar da não linearidade das crises e dos conflitos que marcam seu crescimento.

Sua teoria, na dimensão afetiva, ocupa um lugar central tanto do ponto de vista da construção da pessoa quanto do conhecimento. No que concerne aos procedimentos metodológicos para se ter acesso à pessoa, Wallon elege a observação como instrumento privilegiado da psicologia genética. A observação permite o acesso ao aluno em seus contextos, condição para que se compreenda o real significado de cada uma de suas manifestações: só podemos entender a trama do ambiente na qual está inserida.

Para que se entenda, traz a compreensão do sujeito a partir do seu processo maturacional com importantes contribuições para atendermos as "lacunas" existentes no processo de desenvolvimento do autista, aproximando-o antes, da perspectiva de sujeito e de pessoa, e depois, do transtorno em questão. Este propõe o estudo integrado do desenvolvimento (afetividade, motricidade, inteligência), considerando que o desenvolvimento da criança ocorre em estreita dependência nas relações com o meio.

Para Wallon não é possível falar do pensamento infantil tendo como referência o pensamento do adulto. A atividade mental da criança é qualitativamente diferente do pensamento adulto em inúmeros aspectos. Para o adulto que opera por análise-síntese, o objeto tem uma só imagem constante e estável, qualquer que seja a variabilidade de seus aspectos. Já para a criança, a descontinuidade entre as diferentes imagens de uma mesma realidade, são simultaneamente mais estáticas e múltiplas: a identificação é feita por partes isoladas e é incapaz de transformá-las umas nas outras e de reduzi-las entre si. Nesse sentido, Wallon argumenta que as representações da criança são muito mais firmes, inadequadas e abstratas que as do adulto.

Segundo Wallon, o pensamento infantil é global e pessoal, predominando os critérios afetivos sobre os lógicos e objetivos, o existencial sobre o pensável. É a esse conjunto de traços que se denomina sincretismo, forma de pensamento que se opõe à capacidade 
de análise-síntese própria do pensamento categorial. A superação do pensamento sincrético indiferenciado, rumo ao pensamento categorial, analítico, depende de experiências e aprendizagens e das maturações progressivas do organismo e de suas funções, especialmente da maturação dos centros nervosos no córtex.

De acordo com as características e condições de determinado estágio do desenvolvimento, os processos estarão voltados para o interior ou para o exterior num contínuo movimento de internalização e externalização. É um movimento pendular que possibilita ao sujeito sua construção em direção à autonomia. Ressalta-se ainda, que para Wallon (2007), o desenvolvimento não se encerra no estágio da adolescência, mas permanece em processo ao longo de toda a vida do indivíduo, onde afetividade e cognição estarão sempre em movimento, daí a importância desta abordagem na intervenção pedagógica com crianças autistas.

Sendo características universais do autismo a dificuldade na interação, as alterações na linguagem e nas relações sociais, o comportamento repetitivo e estereotipado, entre outros sintomas, foi possível aplicar nesse processo os recursos da teoria walloniana, que destaca as emoções e a linguagem como domínios funcionais no desenvolvimento da criança. Por essa razão, ressaltou-se a importância de utilizar as ideias de Wallon como possibilidades de uma Intervenção Pedagógica proposta neste trabalho, considerando a possibilidade de perceber os comportamentos de cada aluno através da observação e identificá-los em suas respectivas fases de desenvolvimento.

Em suma, as atitudes e ações que a criança estabelece com o meio familiar e posteriormente com o meio escolar e o meio social devem ser contextualizadas nas relações mútuas, avaliando a dinâmica de interações recíprocas.

A concepção de infância trazida por Wallon foi responsável por se conceber, de outra forma, o processo de desenvolvimento da criança, permitindo revelar, de etapa em etapa, como o pensamento da criança se estrutura, como a afetividade é construída, como a motricidade vai se fazendo aos poucos e como o indivíduo se relaciona com o mundo e com os demais. Estas observações são descritas em uma série de fases que correspondem a um estado transitório de equilíbrio. Nesse sentido, é possível observar no processo das intervenções os avanços que cada criança pode apresentar de acordo com essas fases: 
- Fase impulsiva pura: é uma característica do recém-nascido dada como resposta aos diversos tipos de estímulos

- Fase emocional: por volta dos 6 meses, marcada pela prevalência dos sinais orientados, partindo dos sinais reflexos como choro ou sorriso.

- Fase sensório-motor: final do primeiro ano, início do segundo, prevalece o ato motor no conhecimento dos objetos;

- Fase projetiva: por volta de 2 anos, nessa fase a atividade motora estimula a atividade mental, ou seja, para Wallon é a consciência;

- Fase do personalismo: de 2 anos e meio a 4-5 anos, a criança se desvincula da situação que se encontra implicada tomando "consciência de si";

- Fase da personalidade polivalente: a partir de 6 anos de idade, traz importantes avanços no plano da Inteligência.

O comprometimento de habilidades adquiridas nessas respectivas fases do desenvolvimento humano, seja de ordem psicomotora ou de ordem social, traz sérios prejuízos à realização das atividades cotidianas na vida do indivíduo. Por esse motivo, é preocupante o fato de profissionais da área da educação eventualmente se depararem em suas atividades pedagógicas com alguns fenômenos de comportamento, sem terem conhecimentos suficientes que possam garantir-lhes uma prestação de serviço de maior qualidade.

Wallon destaca as emoções e a linguagem como domínios funcionais no desenvolvimento da criança. Afirma ainda que o desenvolvimento da criança pode ser visto tanto por seus atributos inatos, quanto como um reflexo dos valores sociais. Nesse sentido, a educação deve satisfazer as necessidades orgânicas, relacionais, afetivas e intelectuais para que haja a construção do "eu" e sua relação com o outro e com o mundo dos objetos.

A teoria Walloniana aplicada à intervenção pedagógica ajuda-nos a compreender a essência do pensamento infantil, fundamental para a adequação de postura, intenções e expectativas nas práticas pedagógicas educativas.

"A intervenção pedagógica precisará transcender técnicas e estratégias e criar oportunidades para a valorização da condição humana e para a formação de vínculos; o tratamento médico pode estar baseado no diagnóstico das anomalias, mas a educação deve explorar as potencialidades." (CAMARGOS 2002, p.122) 
A teoria Walloniana propõe uma psicogênese do ser integral, em que todos os aspectos inerentes ao seu desenvolvimento, por mais subjetivos que possam parecer, devem ser observados e compreendidos para que possa haver um real crescimento.

\section{METODOLOGIA}

A intervenção foi realizada no segundo semestre de 2010, com cinco (5) educandos do Centro de Vivência Magnólia da Associação dos Amigos do Autista do Amazonas - AMA, em parceria com o Núcleo de Estudos e Pesquisas em Psicopedagogia Diferencial - NE$\mathrm{PPD} / \mathrm{FACED} / \mathrm{UFAM}$.

O Centro de Vivência Magnólia foi fundado em 29 de maio de 1997, criado pela vontade e necessidade de pais e amigos de autistas de Manaus de se organizar a fim de estruturar um serviço voltado ao atendimento da pessoa com autismo e seus familiares, para minimizar e/ou suprir a carência de serviços terapêutico, pedagógico e social, voltados à referida clientela. Atualmente, a AMA-AM atende 33 alunos com idade de 8 a 42 anos, sendo 4 meninas que permanecem em período integral.

As atividades desenvolvidas pelos autistas no Centro de Vivência Magnólia são: cavalgada, caminhada com obstáculos, noções básicas de computação, oficinas (AVD, horta, jardinagem, culinária, trabalhos manuais), passeios (extramuros), hidroterapia, transporte, alimentação (café, almoço e lanche), educação física, esporte e lazer, avaliação psicopedagógica, atendimento familiar.

Os procedimentos foram realizados a partir dos relatórios apresentados ao Núcleo de Estudos e Pesquisas em Psicopedagogia Diferencial - NEPPD e pelo Centro de Vivência Magnólia - Associação dos Amigos de Autistas do Amazonas - AMA, incluindo informações sobre tratamentos médicos cirúrgicos e outros atendimentos educacionais realizados anteriormente.

As intervenções pedagógicas junto aos cinco educandos autistas do Centro de Vivência Magnólia ocorreram no próprio centro em parceria com o NEPPD/FACED/UFAM. Os educandos que frequentavam a AMA eram assistidos pela Prefeitura de Manaus, contando com transporte que possibilitou a locomoção desses alunos ao Centro Magnólia de segunda a sexta, no decorrer do semestre.

No Centro de Vivência Magnólia, as crianças tomavam café da manhã, tinham aulas ministradas pelos docentes da Secretaria $\mathrm{Mu}-$ 
nicipal de Manaus e recebiam o Atendimento Educacional Especializado de caráter complementar no outro turno oferecido pelo Núcleo de Estudos e Pesquisas em Psicopedagogia Diferencial - NEPPD/UFAM. Desse modo, efetivou-se a parceria entre a AMA e o NEPPD, fortalecendo essa ação de extensão e trazendo benefícios aos educandos atendidos.

Todos os alunos foram atendidos individualmente, por cinco equipes diferentes, em sessões que tiveram a duração de cinquenta minutos cada uma, duas vezes por semana. Cada equipe foi composta por uma pedagoga/psicopedagoga, acompanhada por um/a acadêmico/a do curso de pedagogia, responsável pelos registros referentes às observações, bem como pelas fotografias e filmagens relativas aos atendimentos, orientados e supervisionados pela professora líder da pesquisa. As anotações, realizadas com a devida autorização dos pais e da Instituição, mediante termo de consentimento livre e esclarecido, eram feitas inicialmente em caderno. Após as sessões, pesquisador e acadêmico dedicavam um tempo para organização das anotações (cerca de dez minutos) que eram transcritas para a ficha de registro das atividades daquele caso.

Nesse processo foram utilizados diferentes instrumentos pedagógicos, de acordo com os estágios de desenvolvimento que cada um dos educandos apresentava no início das intervenções, e a cada avanço observado, outros instrumentos eram incluídos, objetivando perceber a superação nos níveis de dificuldades apresentados.

A coleta de dados teve início a partir do acesso aos relatórios apresentados pelo Centro de Vivência Magnólia, no qual constavam os diagnósticos psicopedagógicos e as limitações funcionais dos educandos, assim como as entrevistas feitas com pais e professores. As informações referentes às intervenções pedagógicas foram anotadas a cada atendimento na perspectiva de observar as transformações do comportamento do educando, tendo como foco o desenvolvimento socioemocional e psicomotor e permitindo um acompanhamento minucioso nesse processo.

A despeito de a pesquisa ter sido realizada com cinco autistas, apresentaremos apenas o estudo de três casos, objetivando um melhor detalhamento das ações de intervenção desenvolvidas, e assim relatarmos melhor os efeitos da intervenção educacional em autistas de considerável comprometimento. 


\section{ESTUDOS DE CASOS}

\section{Caso I}

Educando K. S. M., sexo masculino, 8 anos de idade, encontrava-se na fase sensório-motor em que prevalecia o ato motor no conhecimento dos objetos, evoluindo em direção a invenção de condutas próprias na descoberta de novas experiências. Começou a frequentar o Centro desde os seis anos de idade. Apresentava, inicialmente, um comportamento estereotipado, com movimentos repetitivos como: balançar as mãos e balançar o corpo para frente e para trás, fixação do olhar nas mãos por longo tempo, inexistência de comunicação verbal e ausência de expressões faciais. Tinha um alto grau de dependência dos pais para suas atividades diárias de higiene, como escovar os dentes e tomar banho.

\section{Atividades desenvolvidas e resultados obtidos}

\begin{tabular}{|c|c|}
\hline \multicolumn{2}{|c|}{ Educando: K. S. M. } \\
\hline Atividades desenvolvidas & Resultados obtidos \\
\hline $\begin{array}{l}\text { No primeiro momento, } \\
\text { foram expostos materiais } \\
\text { didáticos como: lápis, papel, } \\
\text { borracha, tesoura, pinos, } \\
\text { palitos coloridos, blocos } \\
\text { lógicos, tambor, flauta doce, } \\
\text { com a finalidade de observar } \\
\text { a conduta da criança frente } \\
\text { aos diferentes instrumentos. }\end{array}$ & $\begin{array}{l}\text { A criança, no primeiro momento, frente aos } \\
\text { objetos apresentados, demonstrava timidez, } \\
\text { mas ao perceber a orientação da pesquisadora, } \\
\text { começa a ter interesse em manusear os } \\
\text { instrumentos mostrando predileção pela } \\
\text { flauta e pelo tambor, o que deixou claro seu } \\
\text { interesse pelo som dos instrumentos. }\end{array}$ \\
\hline $\begin{array}{l}\text { Leitura de histórias } \\
\text { infantis, desenhos, recorte, } \\
\text { colagem e pintura. }\end{array}$ & $\begin{array}{l}\text { A criança começa a dar maior atenção à } \\
\text { história lida ou contada, o que se percebeu } \\
\text { através da expressão facial. Demonstrou } \\
\text { interesse também em recortar papel, embora } \\
\text { não apresente ainda total domínio. }\end{array}$ \\
\hline $\begin{array}{l}\text { Quebra-cabeça com partes } \\
\text { do corpo humano. }\end{array}$ & $\begin{array}{l}\text { Neste processo, a criança, pela própria } \\
\text { dificuldade em lidar com o seu corpo } \\
\text { (conhecimento de si), por conta de seus } \\
\text { movimentos estereotipados, também demorou } \\
\text { em perceber a relação das partes do quebra- } \\
\text { cabeça com as do seu próprio corpo. Porém, } \\
\text { no decorrer das intervenções, a criança foi } \\
\text { desenvolvendo maior autonomia em relação } \\
\text { ao seu comportamento geral. O educando } \\
\text { também apresentou evolução em seu quadro } \\
\text { referente à sociabilidade, visto que passou a } \\
\text { interagir, apresentando avanço significativo } \\
\text { do seu interesse pelas atividades propostas. }\end{array}$ \\
\hline
\end{tabular}




\section{Caso II}

L. M. S., educando do sexo masculino, 5 anos de idade, encontrava-se na fase emocional marcada pela prevalência do choro ou sorriso, o que mostrou necessidades afetivas e emocionais. Ao ser encaminhado ao Centro de Vivência, o educando apresentava característica antissocial, dificuldade de comunicação, não atendia a comandos, balbuciava sons incompreensíveis. Às vezes, esses sons eram altos como se estivesse gritando ou chorando. Irritava-se com muita facilidade, em especial quando contrariado. Era um tanto agressivo e intolerante, chegando a atirar alguns materiais pedagógicos nos profissionais que o atendiam.

\section{Atividades desenvolvidas e resultados obtidos}

\begin{tabular}{|l|l|}
\hline \multicolumn{2}{|c|}{ Educando: L.M.S. } \\
\hline \multicolumn{1}{|c|}{ Atividades desenvolvidas } & \multicolumn{1}{c|}{ Resultados obtidos } \\
\hline $\begin{array}{l}\text { No primeiro momento, foram } \\
\text { apresentados alguns materiais } \\
\text { didáticos para a criança como: } \\
\text { revistas infantis, blocos lógicos } \\
\text { e diferentes cores e tamanhos, } \\
\text { lápis, borracha, lápis de cor, } \\
\text { guache, figuras geométricas, } \\
\text { figuras do corpo humano } \\
\text { (boca, nariz, orelha, olhos). }\end{array}$ & $\begin{array}{l}\text { A criança começou a manusear os objetos } \\
\text { grosseiramente, demonstrando sua } \\
\text { irritabidade. Em seguida pegou o lápis } \\
\text { aleatoriamente sem forma definida. Com } \\
\text { o decorrer das sessões, essas atividades } \\
\text { passaram a ter uma regularidade, tanto no } \\
\text { domínio da agressividade, como na forma de se } \\
\text { comunicar com o pesquisador, demonstrando } \\
\text { maior tolerância nas atividades propostas. }\end{array}$ \\
\hline $\begin{array}{l}\text { Pintura com utilização de } \\
\text { guache, massa de modelar, } \\
\text { encaixe com palitos de } \\
\text { plástico, objetos pequenos } \\
\text { com tampa de enroscar. }\end{array}$ & $\begin{array}{l}\text { Nas atividades de pintura, foi possível observar } \\
\text { preferência por cores fortes, utilizando as } \\
\text { mãos, ao invés dos pincéis. Nesse processo, foi } \\
\text { perceptível o extravazamento da agressividade, } \\
\text { levando, posteriormente à possibilidade de } \\
\text { trabalhar mais calmamente com o encaixe } \\
\text { de palitos e o enroscamento das tampas. }\end{array}$ \\
\hline $\begin{array}{l}\text { Utilização de músicas } \\
\text { infantis, parlendas. }\end{array}$ & $\begin{array}{l}\text { A utilização de figuras em associação à } \\
\text { canção possibilitou um equilíbrio em relação } \\
\text { às emoções demonstradas pela criança no } \\
\text { início das intervenções. A sequência rítmica } \\
\text { levou-a a uma aproximação maior com a } \\
\text { pesquisadora, demonstrada pela linguagem } \\
\text { expressiva (emoções) através da confiança e } \\
\text { diminuição da agressividade, respondendo } \\
\text { às atividades sem irritação e com alegria. }\end{array}$ \\
\hline
\end{tabular}

\section{Caso III}

O. C. S. N., educando do sexo masculino de 7 anos e cinco meses de idade, frequentava o Centro há dez meses, encontrava-se na fase sensório-motor, pois não manifestou autonomia para manipular 
objetos sensoriais como caixinha de música, chocalho e telefones. A criança apresentava um comprometimento maior nas relações com outras pessoas, incapacidade de compartilhar sentimentos, gostos e emoções e atraso na fala. Apresentava também comportamentos estereotipados e repetitivos, como o balançar abruptamente as pernas e tronco. Foi percebido que os mesmos comportamentos apareciam mediante agitação, confluência nas reações sobre a interação com o ambiente (excitação), e quando contrariado, a criança demonstrava agressividade.

\section{Atividades desenvolvidas e resultados obtidos}

\begin{tabular}{|l|l|}
\hline \multicolumn{2}{|c|}{ Educando: O. C. S. M. } \\
\hline \multicolumn{1}{|c|}{ Atividades desenvolvidas } & \multicolumn{1}{c|}{ Resultados obtidos } \\
\hline \multirow{2}{*}{$\begin{array}{l}\text { No primeiro momento, foram } \\
\text { apresentados para a criança } \\
\text { alguns materiais didáticos, } \\
\text { como: papel, lápis, borracha, } \\
\text { cola, tesoura, clips, pintura. } \\
\text { apresentados, a criança demonstrava indiferença } \\
\text { e certa resistência em manipular os mesmos. } \\
\text { Apresentou resistência à aproximação do } \\
\text { pesquisador, mantendo-se de cabeça baixa e } \\
\text { sem esboçar reação. Com o prosseguimento } \\
\text { dos encontros, ao perceber a presença } \\
\text { do pesquisador, ela lhe estende a mão e } \\
\text { permanece assim por algum tempo, bem } \\
\text { como, ao chegar, procurava pelos materiais } \\
\text { didáticos para a escrita de garatujas. }\end{array}$} \\
$\begin{array}{l}\text { Relógio, imagens de } \\
\text { momentos rotineiros, como: } \\
\text { refeições, dormir, ir à escola. }\end{array}$ & $\begin{array}{l}\text { Nas atividades onde se trabalhou momentos } \\
\text { de rotina, a criança apontava para o } \\
\text { relógio, demonstrando familiaridade com } \\
\text { o objeto, bem como realizava movimentos } \\
\text { de levar objetos à boca, quando via à sua } \\
\text { frente imagens referentes às refeições; }\end{array}$ \\
\hline $\begin{array}{l}\text { Objetos que produzem som: } \\
\text { telefone, caixa de música, } \\
\text { chocalho. Bolas, que eram } \\
\text { jogadas na direção da criança } \\
\text { para que a mesma devolvesse } \\
\text { para o pesquisador }\end{array}$ & $\begin{array}{l}\text { A criança, no decorrer das sessões, demonstrou } \\
\text { interesse quando o pesquisador manipulava } \\
\text { os objetos sonoros, levando-a a uma maior } \\
\text { aproximação com o pesquisador. Nas } \\
\text { atividades com bola, corria, demonstrando } \\
\text { contentamento, o que possibilitou um } \\
\text { equilíbrio em relação às emoções demonstradas } \\
\text { pela criança no início das intervenções. } \\
\text { Percebeu-se um avanço no comportamento } \\
\text { global, o educando começou a participar } \\
\text { das atividades propostas, embora não } \\
\text { conseguisse se deter por muito tempo em uma } \\
\text { atividade, diminuindo consideravelmente sua } \\
\text { agressividade, mesmo quando contrariado. }\end{array}$ \\
\hline & \\
\hline
\end{tabular}

$\mathrm{Na}$ impossibilidade de relatarmos todos os encontros, uma vez que a intervenção teve a duração de seis meses, com cerca de oito encontros mensais, optamos por relatar os encontros iniciais e os resultados obtidos ao final das intervenções. 


\section{Intervenções pedagógicas operacionalizadas:}

\begin{tabular}{|c|c|c|}
\hline Área & Instrumento utilizado & Objetivos \\
\hline $\begin{array}{l}\text { Motricidade } \\
\text { fina }\end{array}$ & $\begin{array}{l}\text { Bola de gude, pintura com gua- } \\
\text { che, massa de modelar, alinhavo, } \\
\text { pinos, palitos coloridos; objetos } \\
\text { pequenos com tampas de rosca. } \\
\text { Jogos: de encaixe, faz de conta. } \\
\text { Blocos lógicos. Canudos, barbante, } \\
\text { tesoura, clips, cartas de baralho. }\end{array}$ & $\begin{array}{l}\text { Fazer o educando conhecer } \\
\text { as cores, desenvolver as ha- } \\
\text { bilidades motoras manuais, } \\
\text { atenção e concentração. }\end{array}$ \\
\hline $\begin{array}{l}\text { Motricidade } \\
\text { Grossa }\end{array}$ & $\begin{array}{l}\text { Bolas de tamanho médio e grande, } \\
\text { escada, obstáculos para pular, mo- } \\
\text { vimentos de sentar e levantar, cor- } \\
\text { rer e virar para a direita/esquerda. }\end{array}$ & $\begin{array}{l}\text { Desenvolver habilidades } \\
\text { motoras dos membros } \\
\text { inferiores, melhorar o equi- } \\
\text { líbrio global do educando. }\end{array}$ \\
\hline $\begin{array}{l}\text { Coordenação } \\
\text { visomotora }\end{array}$ & $\begin{array}{l}\text { Figuras geométricas, fo- } \\
\text { lhas de papel, lápis. }\end{array}$ & $\begin{array}{l}\text { Observar aspectos psi- } \\
\text { comotores e espaciais, a } \\
\text { percepção tátil e visual, } \\
\text { o reconhecimento de } \\
\text { cores do educando. }\end{array}$ \\
\hline Lateralidade & $\begin{array}{l}\text { Partes do corpo: mãos, braços, } \\
\text { pés; peça de papel duro com furo } \\
\text { no meio; caneta, borracha, cola. }\end{array}$ & $\begin{array}{l}\text { Observar se a criança } \\
\text { identifica direita e es- } \\
\text { querda no seu corpo e } \\
\text { no corpo do outro. }\end{array}$ \\
\hline $\begin{array}{l}\text { Esquema } \\
\text { corporal }\end{array}$ & $\begin{array}{l}\text { Os momentos de um dia, } \\
\text { material para desenho, mú- } \\
\text { sicas infantis, parlendas. }\end{array}$ & $\begin{array}{l}\text { Observar se o educan- } \\
\text { do tem capacidade para } \\
\text { desenhar o próprio } \\
\text { corpo ou partes dele. }\end{array}$ \\
\hline $\begin{array}{l}\text { Orientação } \\
\text { Temporal }\end{array}$ & $\begin{array}{l}\text { Calendário, agenda do estu- } \\
\text { dante, fotografias, relógio, fi- } \\
\text { guras de momentos de rotina: } \\
\text { refeições, dormir, ir à escola. }\end{array}$ & $\begin{array}{l}\text { Observar se o educan- } \\
\text { do tem a capacidade } \\
\text { de situar-se no tempo, } \\
\text { identificando momentos } \\
\text { da sua rotina diária. }\end{array}$ \\
\hline $\begin{array}{l}\text { Orientação } \\
\text { espacial }\end{array}$ & $\begin{array}{l}\text { Quebra-cabeças, cartões com } \\
\text { figuras iguais, figuras de planta } \\
\text { de uma casa, sala de aula, etc. }\end{array}$ & $\begin{array}{l}\text { Observar se o educando é } \\
\text { capaz de situar-se no es- } \\
\text { paço, identificando locais } \\
\text { onde se mora e dorme, e } \\
\text { que estratégias de racio- } \\
\text { cínio ele desenvolve. }\end{array}$ \\
\hline $\begin{array}{l}\text { Sequência } \\
\text { Lógica }\end{array}$ & $\begin{array}{l}\text { Cartões com sequências de figu- } \\
\text { ras, números, histórias infantis. }\end{array}$ & $\begin{array}{l}\text { Observar se o educando } \\
\text { identifica uma sequência ló- } \\
\text { gica numérica ou histórica. }\end{array}$ \\
\hline $\begin{array}{l}\text { Avaliação da } \\
\text { consciência } \\
\text { fonológica }\end{array}$ & $\begin{array}{l}\text { Cartões com palavras e ima- } \\
\text { gens que terminam com o } \\
\text { mesmo som, ou rima, coloca- } \\
\text { dos de forma intercalada. }\end{array}$ & $\begin{array}{l}\text { Identificar se o educando } \\
\text { tem consciência da ter- } \\
\text { minação das palavras à } \\
\text { sua frente: sons e rimas } \\
\text { iguais e diferentes. }\end{array}$ \\
\hline
\end{tabular}




\section{CONCLUSÃO E CONSIDERAÇÕES FINAIS}

O desenvolvimento deste projeto levou-nos à compreensão da importância que teve a intervenção pedagógica embasada na teoria de Henri Wallon com os educandos autistas. Tendo em vista que esta teoria orienta o trabalho com o ser humano de forma global, o projeto possibilitou a realização de atividades voltadas para o desenvolvimento do esquema corporal, que envolve a afetividade, as emoções e a cognição.

As intervenções realizadas foram experiências significativas para todos os colaboradores envolvidos, pois nos proporcionaram uma visão diferente e mais ampla em relação ao autismo e às singularidades das crianças autistas.

Ressaltamos algumas dificuldades enfrentadas nos primeiros contatos, pois as crianças não conheciam os integrantes da equipe de trabalho e, com a mudança de rotina, algumas demonstraram agressividade e irritação. Essa conduta permitiu refletir sobre a intervenção pedagógica e psicopedagógica para alunos autistas enquanto ação desafiadora, que exige conhecimento específico, reflexão, mas, sobretudo, domínio das técnicas de intervenção; entretanto, como consta nos relatos dos casos, todos os educandos evidenciaram melhora em seus comportamentos em relação ao início das intervenções.

Buscamos adequar as diferentes maneiras de intervenção junto aos educandos autistas, interpretando comportamentos e gradativamente oferecendo atividades estimulantes - condições necessárias - para que os educandos se desenvolvessem descobrindo novos modos de comunicação e relacionamento com os outros e com o meio, promovendo um melhor desempenho em suas tarefas cotidianas e a funcionalidade de suas ações.

O trabalho também possibilitou espaço aos discentes das áreas de educação da Universidade Federal do Amazonas - UFAM, para uma atuação satisfatória como equipe interdisciplinar, ou seja, buscando uma única linguagem, e tendo como tarefa principal lidar com pessoas que apresentam necessidades especiais. Assim, através de intervenções pedagógicas, foi possível estimular essas pessoas a uma maior interação com o seu meio e melhor convivência no cotidiano.

Dessa forma, este trabalho buscou na obra de Henri Wallon, em sua Teoria das Emoções e da Psicogênese, embasamento para uma intervenção pedagógica que contemplasse todos os aspectos do desenvolvimento do educando, de modo a proporcionar-lhe um ambiente que oferecesse condições de real crescimento e participação efetiva no meio social. 
Para Wallon, o trabalho de intervenção pedagógica precisa ter uma carga de sentimento e a emotividade é imprescindível. A teoria sugere métodos de ensino que considerem adequação às capacidades do aluno. Nesse sentido, Wallon, na obra "A evolução psicológica da criança", afirma que a criança sabe senão viver a sua infância. Conhecê-la, pertence ao adulto. Mas o que vai prevalecer nesse conhecimento: o ponto de vista do adulto ou da criança? (WALLON, 1968, p.11)

A incumbência de compreender, conhecer e estudar o universo da criança autista foi dos profissionais da educação comprometidos com o projeto, respeitando sempre a evolução de cada indivíduo. Nesse sentido, buscamos sempre anotar um olhar diferente, uma fala diferente, um sorriso, a manipulação de um objeto diferente e assim a possibilidade da interação social estabelecida entre aluno e educador. Compreendemos que a teoria Walloniana enfatiza o aproveitamento das possibilidades de cada fase de desenvolvimento e nos exigiu propostas de procedimentos diversificados para cada idade cognitiva que cada aluno se encontrava.

\section{Notas}

- NEPPD - Núcleo de Estudos e Pesquisas em Psicopedagogia Diferencial

- FACED - Faculdade de Educação

- UFAM - Universidade Federal do Amazonas

- AMA - Associação dos Amigos Autistas do Amazonas 


\section{REFERÊNCIAS BIBLIOGRÁFICAS}

ALMEIDA, L.R. Cognição Corpo e Afeto. Revista Educação: História da Pedagogia-Henri Wallon, p.20-31, 2010.

ASSOCIAÇÃO PSIQUIÁTRICA AMERICANA - Manual diagnóstico e estatístico de transtornos mentais. DSM-IV - Porto Alegre: Artmed, 2004.

ASSUMPÇÃO, Jr., F.B. - Brief report: a case of chromosome 22 alteration associated with autistic syndrome. Journal of Austism and Developmental Disorders, v.28, n.3, p.253-256, 1998.

BLEULER, E. Dementia Praecox oder Gruppe der Schizophrenien (Special Part, division 4.1 of Handbuch der Psychiatrie, general ed. G. von Aschaffenburg) (Leipzig, Vienna: Deutike), 1911.

BOATO. E.M. Henri Wallon e a Deficiência Múltipla: uma proposta de intervenção pedagógica. São Paulo: Loyola, 2009.

BRASIL. Ministério da Educação. Secretaria de educação especial. Política Nacional de Educação Especial. Brasília: Secretaria de Educação Especial, 1994.

CAMARGOS, W. Jr.(org.) Transtornos Invasivos do Desenvolvimento: $3^{\circ}$ Milênio. Brasília: Ministério da Justiça, Coordenadoria Nacional para Integração da Pessoa Portadora de Deficiência, AMES, ABRA, 2002.

CHICON, J.F. Práticas Psicopedagógicas em crianças com necessidades educacionais especiais - abordagem psicomotora. Vitória-ES: UFES-Centro de Educação Física e Desportos, 1999.

DANTAS, H. A Infância da Razão: uma introdução à psicologia da inteligência de Henri Wallon. São Paulo: Manole Dois, 1990.

DANTAS, H.; LA TAILLE, Y.; OLIVEIRA, M.K. Piaget, Vygotsky, Wallon. Teorias psicogenéticas em discussão. 3. ed. São Paulo: Summus, 1992.

FRITH, U. Autism and Asperger Syndrome. Cambridge, UK: University Press, 1996.

GALVÃO, I. Henri Wallon: uma concepção dialética do desenvolvimento infantil. Petrópolis, Rio de Janeiro: Vozes, 1998.

MARQUES, E.C. Perturbações do Espectro do Autismo - ensaios de uma intervenção construtivista desenvolvimentista com mães. Coimbra: Portugal Quarteto, 2000.

OLIVEIRA, C.A. Os Onze Casos de Kanner. Porto Alegre: UFRGS, 2001.

ORGANIZAÇÃO MUNDIAL DE SAÚDE. Classificação de transtornos mentais e de comportamento do CID-10: descrições clínicas e diretrizes diagnósticas. Porto Alegre: Artes Médicas, 1993.

SCHWARTZMAN, J.S. Autismo Infantil. Brasília: CORDE, 1994.

WALLON, H. As Origens do caráter na criança. São Paulo: Difusão Européia do Livro, 1971. 
A Evolução Psicológica da Criança. São Paulo: Martins Fontes, 2007.

WING, L. O contínuo das características autistas. In: Gardener, J.C. (Org.). Autismo e outros atrasos do desenvolvimento. Uma atualização para os que atuam na área: do especialista aos pais. Brasília: MAS/CORDE, 1993, p.90-95. 